Acta Crystallographica Section C

Crystal Structure

Communications

ISSN 0108-2701

\section{$1 \lambda^{4}, 4 \lambda^{4}, 8 \lambda^{4}, 11 \lambda^{4}$-Tetrathiacyclotetra- decane-1,4,7,10-tetraylidenetetra- aminium tetrakis(2,4,6-trimethyl- benzenesulfonate)}

\author{
Sophie H. Dale, ${ }^{a}$ Mark R. J. Elsegood, ${ }^{b}$ Liam M. Gilby, \\ Kathryn E. Holmes ${ }^{b}$ and Paul F. Kelly ${ }^{b *}$ \\ ${ }^{\text {a }}$ School of Natural Sciences, University of Newcastle-upon-Tyne, Newcastle-upon- \\ Tyne NE1 7RU, England, and ' ${ }^{\mathbf{b}}$ Chemistry Department, Loughborough University, \\ Loughborough, Leicestershire LE11 3TU, England \\ Correspondence e-mail: p.f.kelly@lboro.ac.uk
}

Received 24 March 2005

Accepted 5 May 2005

Online 31 May 2005

Investigations of the reactivity of the thio-crown [14] $\mathrm{aneS}_{4}$ (1,4,8,11-tetrathiacyclotetradecane) towards the aminating agent $o$-mesitylsulfonylhydroxylamine have lead to the crystallization of $1 \lambda^{4}, 4 \lambda^{4}, 8 \lambda^{4}, 11 \lambda^{4}$-tetrathiacyclotetradecane1,4,7,10-tetraylidenetetraaminium tetrakis(2,4,6-trimethylbenzenesulfonate), $\mathrm{C}_{10} \mathrm{H}_{28} \mathrm{~N}_{4} \mathrm{~S}_{4}{ }^{4+} \cdot 4 \mathrm{C}_{9} \mathrm{H}_{11} \mathrm{O}_{3} \mathrm{~S}^{-}$. The compound crystallizes in a centrosymmetric space group, with half a formula unit in the asymmetric unit. All S atoms within the cationic component are aminated, with the four $\mathrm{NH}_{2}$ substituents arranged in pairs on neighbouring $\mathrm{S}$ atoms on opposite faces of the crown. The macrocyclic cation in the compound forms hydrogen bonds with the 2,4,6-trimethylbenzenesulfonate anions to create chains, which are further linked into thick two-dimensional sheets.

\section{Comment}

As part of an ongoing investigation into the chemistry of novel sulfimide systems, we have recently investigated the reactivity of the thio-crown [9] $\mathrm{aneS}_{3}$ (1,4,7-trithiacyclononane) towards species capable of forming $\mathrm{S}-\mathrm{N}$ bonds via reaction at thioether units (Elsegood et al., 2002; Aucott et al., 2004). In the case of the aminating agent MSH (o-mesitylsulfonylhydroxylamine), reaction on an equimolar scale generated a salt of the protonated sulfimide cation $\left\{[9] \mathrm{aneS}_{2} \mathrm{~S}\left(\mathrm{NH}_{2}\right)\right\}^{+}$ (with the $\left[\mathrm{Me}_{3} \mathrm{C}_{6} \mathrm{H}_{2} \mathrm{SO}_{3}\right]^{-}$anion which results from all MSH reactions; Elsegood et al., 2002). While further addition of one equivalent of $\mathrm{MSH}$ resulted in $\left\{[9 \text {-ane }] \mathrm{SS}\left(\mathrm{NH}_{2}\right) \mathrm{S}\left(\mathrm{NH}_{2}\right)\right\}^{2+}$, addition of a third equivalent generated the $\left\{[9\right.$-ane $] \mathrm{S}\left(\mathrm{NH}_{2}\right)$ $\left.\mathrm{S}_{2}(\mu-\mathrm{N})\right\}^{2+}$ cation (in which an $\mathrm{N}$ atom bridges two of the $\mathrm{S}$ atoms $)$, rather than the expected trisulfimidium cation $\{[9$-ane $]$ $\left.\left[\mathrm{S}\left(\mathrm{NH}_{2}\right)\right]_{3}\right\}^{3+}$. The reason for the latter reaction is not clear, although one possibility is that a combination of high charge and small ring size within the latter putative species destabilizes it relative to the transannularly bridged compound.
In order to gain some insight into the above observations, we have now investigated analogous reactions of the larger crown species [14] ane $\mathrm{S}_{4}$ (1,4,8,11-tetrathiacyclotetradecane), observing the products formed when an excess of MSH is added. In this case, the fully aminated title product, [\{[14]ane$\left.\left.\left[\mathrm{S}\left(\mathrm{NH}_{2}\right)\right]_{4}\right\}^{4+}\right]\left[\mathrm{C}_{6} \mathrm{Me}_{3} \mathrm{SO}_{3}^{-}\right]_{4}, \quad(\mathrm{I})$, results and its crystal structure is presented here.

$$
[
$$<smiles>CCCS(=N)CCCS(=N)(=N)CCCS(=N)(=N)CCC</smiles>

(I)

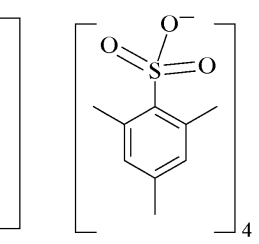

4
Compound (I) crystallizes in a centrosymmetric space group with half a formula unit in the asymmetric unit (Fig. 1 and Table 1). The macrocyle is substituted with one $\mathrm{NH}_{2}$ group on each of the $\mathrm{S}$ atoms in the ring and lies on an inversion centre. The $\mathrm{NH}_{2}$ substituents are arranged in pairs on neighbouring $\mathrm{S}$ atoms on opposite faces of the crown. The two unique 2,4,6-trimethylbenzenesulfonate anions are almost perpendicular with respect to each other [the dihedral angle between the two aromatic rings is $\left.89.4(2)^{\circ}\right]$. The macrocyle was found to be disordered and was refined with atoms C4, N2 and $\mathrm{C} 5$ (and their associated $\mathrm{H}$ atoms) modelled over two sets of positions [major refined occupancy $59.5(7) \%$ ]. The $\mathrm{SO}_{3}^{-}$ groups of the two unique anions were also found to be disordered. The $\mathrm{SO}_{3}^{-}$group containing atom $\mathrm{S} 4$ was modelled over two sets of positions with a coincident $\mathrm{S}$ atom. The major refined occupancy of this group was found to be equal to that of the cation (due to hydrogen bonding between the disordered portion of the cation and this anion) and, therefore, the two occupancies were refined collectively. The $\mathrm{SO}_{3}^{-}$group containing atom S3 was modelled in a similar manner, with a major refined occupancy of 72 (3)\%. In the following analysis

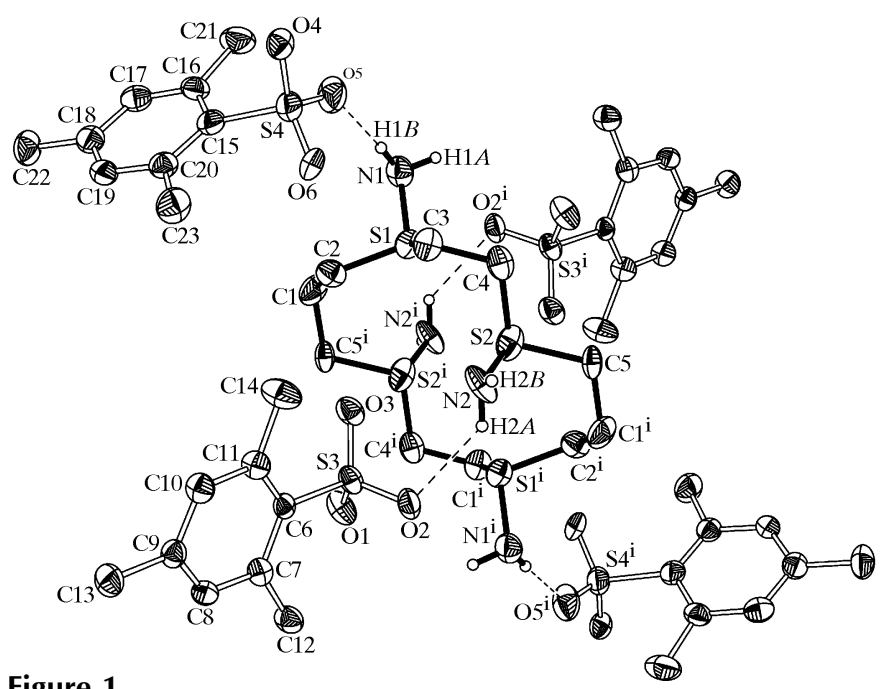

Figure 1

A view of (I), showing the atom-labelling scheme. $\mathrm{H}$ atoms (except for $\mathrm{NH}$ ) and the minor component of the disorder model have been omitted for clarity. Displacement ellipsoids are drawn at the $40 \%$ probability level. Hydrogen bonds are shown as dashed lines. [Symmetry code: (i) $1-x,-y, 1-z$.] 
Figure 2

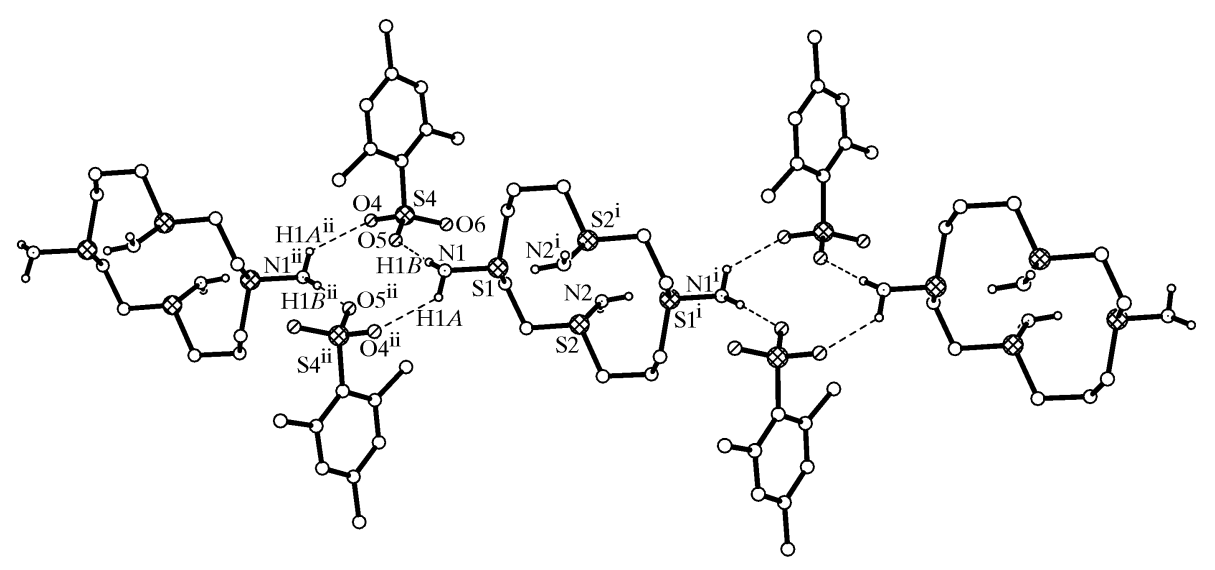

The hydrogen-bonded chains of (I), formed from cations and symmetry equivalents of the anion containing atom S4, viewed along the [110] direction. The minor component of the disorder model, the anion containing atom S3 and $\mathrm{H}$ atoms except for NH have been omitted for clarity. Hydrogen bonds are shown as dashed lines. [Symmetry codes: (i) $1-x,-y, 1-z$; (ii) $2-x, 1-y, 1-z$.]

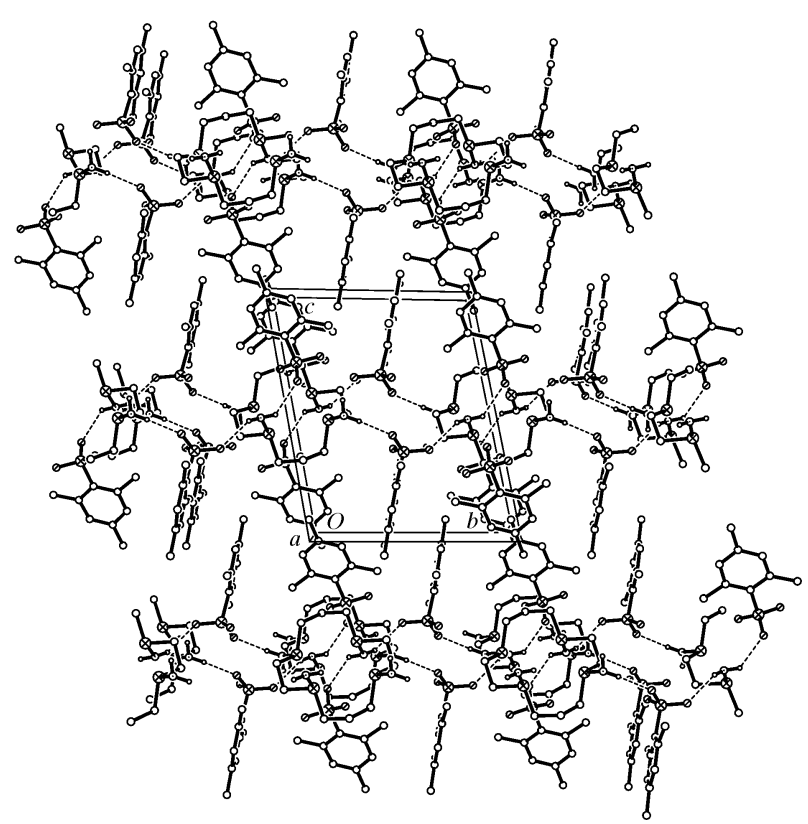

Figure 3

A packing plot of (I), viewed along the crystallographic $a$ axis $(b$ axis horizontal). The minor component of the disorder model and $\mathrm{H}$ atoms except for NH have been omitted for clarity. Hydrogen bonds are shown as dashed lines.

of the geometry and hydrogen bonding of compound (I), only the major component of the disorder model will be discussed.

The $\mathrm{NH}_{2}$ groups in (I) are involved in $\mathrm{N}-\mathrm{H} \cdots \mathrm{O}$ hydrogen bonds with the $\mathrm{SO}_{3}^{-}$groups of the 2,4,6-trimethylbenzenesulfonate anions (Table 2). Hydrogen bonds utilizing the $\mathrm{NH}_{2}$ group containing atom $\mathrm{N} 1$ and the $\mathrm{SO}_{3}^{-}$group containing atom S4 create a 12-membered hydrogen-bonded ring motif containing four $\mathrm{N}-\mathrm{H}$ donor groups and four $\mathrm{O}$ acceptors, giving an $R_{4}^{4}(12)$ graph-set motif (Fig. 2; Etter, 1990; Etter et al., 1990; Bernstein et al., 1995). A recent study of supramolecular synthons in organic sulfonate structures in the Cambridge Structural Database (Haynes et al., 2004) has highlighted this hydrogen-bonded ring motif as the most common in sulfonate compounds containing $\mathrm{NH}$ donors, occurring in $17.85 \%$ of all sulfonate-NH donor crystal structures. The $R_{4}^{4}(12)$ motifs link alternating cations and anions (containing atoms $\mathrm{S} 4, \mathrm{O} 4, \mathrm{O} 5$ and O6) into chains. Hydrogen bonds utilizing the $\mathrm{NH}_{2}$ group containing atom $\mathrm{N} 2$ link these chains into a thick two-dimensional sheet arrangement, in which the crown cations are sandwiched between two layers of anions. The sheets propagate in the crystallographic $a b$ plane (Fig. 3). The $\mathrm{O}$ atoms of the sulfonate groups also have close contacts with the $\mathrm{S}$ atoms of the crown cation, with $\mathrm{O} \cdots \mathrm{S}$ distances in the range 3.18 (3)-3.674 (13) ̊.

The results of a search of the Cambridge Structural Database (CSD, Version 5.26, February 2005 update; Allen, 2002; Fletcher et al., 1996) for tetrasubstituted [14]aneS $\mathrm{a}_{4}$ crown species, similar to the cationic component of compound (I), are shown in Table 3. There are very few suitable entries in the CSD which are not metal-coordinated species, and so all entries have been included in the analysis. The $\mathrm{C}-\mathrm{C}$ and $\mathrm{S}-\mathrm{C}$ bond lengths of the cationic species in (I) show good similarities to those shown in Table 3, although it should be noted that restraints have been applied to the bond lengths of the cation due to the disorder present.

It is not immediately obvious why there should be the contrasting reactivity of an excess of MSH towards trithia and tetrathia crowns. On the basis of the trithia crown reactions, one might have expected the fully substituted ring in (I) to rearrange (via loss of ammonium ions) to lower-charged $\mathrm{N}$ bridged systems analagous to the $\left\{[9 \text {-ane }] \mathrm{S}\left(\mathrm{NH}_{2}\right) \mathrm{S}_{2}(\mu-\mathrm{N})\right\}^{2+}$ cation noted above. That it does not presumably indicates that there are many factors to consider within the energetics of such systems. Further investigations into such effects are underway.

\section{Experimental}

The title compound was prepared by addition of an excess (i.e. more than four molar equivalents) of $\mathrm{MSH}$ to [14]ane $\mathrm{S}_{4}$, in a manner analogous to previously published reactions of [9] $\mathrm{aneS}_{3}$ (Elsegood $e t$ al., 2002; Aucott et al., 2004). Compound (I) was crystallized by slow diffusion of diethyl ether into an acetonitrile solution of the compound. 


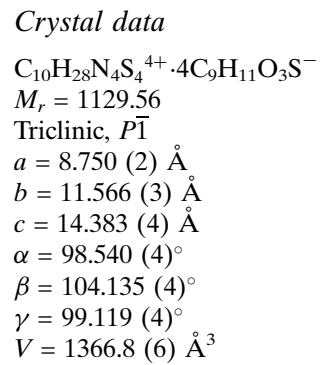

$Z=1$

$D_{x}=1.372 \mathrm{Mg} \mathrm{m}^{-3}$

Mo $K \alpha$ radiation

Cell parameters from 1398 reflections

$\theta=2.5-26.7^{\circ}$

$\mu=0.39 \mathrm{~mm}^{-1}$

$T=150(2) \mathrm{K}$

Needle, colourless

$0.09 \times 0.02 \times 0.01 \mathrm{~mm}$

Data collection

Bruker SMART 1000 CCD

diffractometer

$\omega$ rotation scans with narrow frames

Absorption correction: multi-scan

(SADABS; Sheldrick, 2003)

$T_{\min }=0.945, T_{\max }=0.996$

10556 measured reflections

\section{Refinement}

Refinement on $F^{2}$

$R\left[F^{2}>2 \sigma\left(F^{2}\right)\right]=0.077$

$w R\left(F^{2}\right)=0.233$

$S=1.01$

5312 reflections

424 parameters

$\mathrm{H}$ atoms treated by a mixture of independent and constrained refinement

5312 independent reflections 2257 reflections with $I>2 \sigma(I)$

$R_{\text {int }}=0.075$

$\theta_{\max }=26.0^{\circ}$

$h=-10 \rightarrow 10$

$k=-13 \rightarrow 14$

$l=-17 \rightarrow 17$

$$
\begin{aligned}
& w=1 /\left[\sigma^{2}\left(F_{\mathrm{o}}{ }^{2}\right)+(0.0916 P)^{2}\right. \\
& +1.6284 P] \\
& \text { where } P=\left(F_{\mathrm{o}}{ }^{2}+2 F_{\mathrm{c}}{ }^{2}\right) / 3 \\
& (\Delta / \sigma)_{\max }<0.001 \\
& \Delta \rho_{\max }=0.56 \mathrm{e}^{-3} \\
& \Delta \rho_{\min }=-0.56 \mathrm{e} \AA^{-3}
\end{aligned}
$$

Table 1

Selected geometric parameters $(\AA)$.

\begin{tabular}{llll}
\hline $\mathrm{C} 1-\mathrm{C} 5^{\mathrm{i}}$ & $1.550(8)$ & $\mathrm{S} 1-\mathrm{C} 3$ & $1.786(5)$ \\
$\mathrm{C} 1-\mathrm{C} 2$ & $1.551(7)$ & $\mathrm{S} 2-\mathrm{N} 2$ & $1.705(6)$ \\
$\mathrm{C} 3-\mathrm{C} 4$ & $1.554(9)$ & $\mathrm{S} 2-\mathrm{C} 4$ & $1.770(6)$ \\
$\mathrm{S} 1-\mathrm{N} 1$ & $1.676(6)$ & $\mathrm{S} 2-\mathrm{C} 5$ & $1.772(5)$ \\
$\mathrm{S} 1-\mathrm{C} 2$ & $1.782(5)$ & & \\
\hline
\end{tabular}

Symmetry code: (i) $1-x,-y, 1-z$.

\section{Table 2}

Hydrogen-bond geometry $\left(\AA{ }^{\circ}\right)$.

\begin{tabular}{lllll}
\hline$D-\mathrm{H} \cdots A$ & $D-\mathrm{H}$ & $\mathrm{H} \cdots A$ & $D \cdots A$ & $D-\mathrm{H} \cdots A$ \\
\hline $\mathrm{N} 1-\mathrm{H} 1 A \cdots \mathrm{O} 4^{\mathrm{ii}}$ & $0.89(2)$ & $2.40(6)$ & $3.090(12)$ & $135(6)$ \\
$\mathrm{N} 1-\mathrm{H} 1 A \cdots \mathrm{O} 4 X^{\text {ii }}$ & $0.89(2)$ & $2.02(6)$ & $2.683(12)$ & $130(6)$ \\
$\mathrm{N} 1-\mathrm{H} 1 B \cdots \mathrm{O} 5$ & $0.90(2)$ & $2.01(2)$ & $2.905(11)$ & $177(7)$ \\
$\mathrm{N} 1-\mathrm{H} 1 B \cdots \mathrm{O} 5 X$ & $0.90(2)$ & $1.85(4)$ & $2.681(9)$ & $154(7)$ \\
$\mathrm{N} 2-\mathrm{H} 2 A \cdots \mathrm{O} 2$ & $0.90(2)$ & $2.25(10)$ & $2.969(19)$ & $136(12)$ \\
$\mathrm{N} 2-\mathrm{H} 2 B \cdots \mathrm{O} 4{ }^{\text {iii }}$ & $0.89(2)$ & $2.19(8)$ & $2.897(15)$ & $136(10)$ \\
$\mathrm{N} 2 X-\mathrm{H} 2 C \cdots \mathrm{O} 1 X^{\mathrm{i}}$ & $0.90(2)$ & $2.39(13)$ & $3.10(4)$ & $136(15)$ \\
\hline
\end{tabular}

Symmetry codes: (i) $1-x,-y, 1-z$; (ii) $2-x, 1-y, 1-z$; (iii) $1-x, 1-y, 1-z$.

Aromatic $\mathrm{H}(\mathrm{C}-\mathrm{H}$ distance $=0.95 \AA)$ and methyl $\mathrm{H}(\mathrm{C}-\mathrm{H}$ distance $=0.98 \AA$ ) atoms were placed in geometric positions using a riding model. NH $\mathrm{H}$ atoms were located in a difference Fourier map and refined using restraints on the $\mathrm{N}-\mathrm{H}$ bond length [target value 0.90 (2) $\AA$ ] and 1,3-distances (SHELXTL SADI restraint; Sheldrick, 2000). $U_{\text {iso }}(\mathrm{H})$ values were set at $1.2 U_{\text {eq }}(\mathrm{C}, \mathrm{N})$ for aryl and $\mathrm{NH} \mathrm{H}$ atoms, and $1.5 U_{\text {eq }}(\mathrm{C})$ for methyl $\mathrm{H}$ atoms. The data set was truncated at $2 \theta=52^{\circ}$, as only statistically insignificant data were present above this limit. Low bond precision and a low observed/unique ratio have resulted from poor crystal quality and weak data at higher angles. The macrocycle and both unique $\mathrm{SO}_{3}^{-}$groups were found to be dis-
Table 3

$\mathrm{S}-\mathrm{C}$ and $\mathrm{C}-\mathrm{C}$ bond lengths $(\AA)$ for tetrasubstituted [14]aneS $\mathrm{C}_{4}$ crown species, obtained from a search of the CSD (Version 5.26, February 2005 update; Allen, 2002).

The ranges of the $\mathrm{S}-\mathrm{C}$ and $\mathrm{C}-\mathrm{C}$ bond lengths are shown, with the average values in parentheses. The labels Ethyl and Propyl are used to distinguish between the two- and three-carbon bridges in the crown molecule. The statistics are taken from a small population of six structures containing tetrasubstituted crowns.

\begin{tabular}{lll}
\hline Bridge & $\mathrm{S}-\mathrm{C}$ & $\mathrm{C}-\mathrm{C}$ \\
\hline Ethyl & $1.808-1.825[1.818(6)]$ & $1.500-1.545[1.523(16)]$ \\
Propyl & $1.804-1.818[1.813(4)]$ & $1.499-1.533[1.518(13)]$ \\
\hline
\end{tabular}

ordered. Atoms $\mathrm{C} 4, \mathrm{C} 5, \mathrm{~N} 2, \mathrm{H} 2 A$ and $\mathrm{H} 2 B$ of the macrocyle and atoms $\mathrm{O} 4, \mathrm{O} 5$ and $\mathrm{O} 6$ of one anion were modelled over two sets of positions with a refined major occupancy of 59.5 (7)\%. Atoms O1, O2 and $\mathrm{O} 3$ of the second anion were modelled over two sets of positions with a refined major occupancy of $72(3) \%$. This second refined occupancy was less precisely determined due to fewer atoms within the disorder model. Restraints were applied to the $\mathrm{S}-\mathrm{C}, \mathrm{C}-\mathrm{C}$ and $\mathrm{S}-\mathrm{N}$ bond lengths of the macrocycle, and $\mathrm{S}-\mathrm{O}$ bond lengths were refined to be approximately $1.44 \AA$ (a CSD search for $\mathrm{S}-\mathrm{O}$ bond lengths in arylsulfonates gave a mean of $1.44 \AA$ from 964 hits). Restraints were applied to the anisotropic displacement parameters of all $\mathrm{S}$ and $\mathrm{O}$ atoms.

Data collection: SMART (Bruker, 2001); cell refinement: SAINT (Bruker, 2001); data reduction: $S A I N T$; $\operatorname{program}(\mathrm{s})$ used to solve structure: SHELXTL (Sheldrick, 2000); program(s) used to refine structure: SHELXTL; molecular graphics: SHELXTL; software used to prepare material for publication: $S H E L X T L$ and local programs.

The authors acknowledge the EPSRC for a Postdoctoral Research Assistantship (LMG) and the use of the EPSRC's Chemical Database Service at Daresbury (Fletcher et al., 1996).

Supplementary data for this paper are available from the IUCr electronic archives (Reference: SQ1209). Services for accessing these data are described at the back of the journal.

\section{References}

Allen, F. H. (2002). Acta Cryst. B58, 380-388.

Aucott, S. M., Bailey, M. R., Elsegood, M. R. J., Gilby, L. M., Holmes, K. E., Kelly, P. F., Papageorgiou, M. J. \& Pedrón-Haba, S. (2004). New J. Chem. pp. 959-966.

Bernstein, J., Davis, R. E., Shimoni, L. \& Chang, N.-L. (1995). Angew. Chem. Int. Ed. Engl. 34, 1555-1573.

Bruker (2001). SMART (Version 5.611) and SAINT (Version 6.02a). Bruker AXS Inc., Madison, Wisconsin, USA.

Elsegood, M. R. J., Holmes, K. E., Gilby, L. M. \& Kelly, P. F. (2002). Can. J. Chem. 18, 1410-1414.

Etter, M. C. (1990). Acc. Chem. Res. 23, 120-126.

Etter, M. C., MacDonald, J. C. \& Bernstein, J. (1990). Acta Cryst. B46, 256-262.

Fletcher, D. A., McMeeking, R. F. \& Parkin, D. (1996). J. Chem. Inf. Comput. Sci. 36, 746-749.

Haynes, D. A., Chisholm, J. A., Jones, W. \& Motherwell, W. D. S. (2004). CrystEngComm, 6, 584-588.

Sheldrick, G. M. (2000). SHELXTL. Version 6.10. Bruker AXS Inc., Madison, Wisconsin, USA.

Sheldrick, G. M. (2003). SADABS. Version 2.10. University of Göttingen, Germany. 